\title{
Effectiveness of group counseling with Acceptance and Commitment Therapy (ACT) on sexual Satisfaction of HIV positive women and women with HIV positive husband
}

\section{mahshid Bokaie}

Shahid Sadoughi University of Medical Sciences and Health Services Yazd Research and Clinical Centre for Infertility

naieralsadat tahery ( $\nabla$ taherynaier@yahoo.com )

Shahid Sadoughi University of Medical Sciences and Health Services Yazd Research and Clinical Centre for Infertility https://orcid.org/0000-0001-9784-336X

mariam Dafeei

Shahid Sadoughi University of Medical Sciences and Health Services Yazd Research and Clinical Centre for Infertility

\section{Research article}

Keywords: HIV, ACT, Acceptance and Commitment Therapy, Sexual Satisfaction.

Posted Date: April 28th, 2020

DOI: https://doi.org/10.21203/rs.3.rs-23797/v1

License: (c) (i) This work is licensed under a Creative Commons Attribution 4.0 International License.

Read Full License 
The main title of the article:

Effectiveness of group counseling with Acceptance and Commitment Therapy (ACT) on sexual Satisfaction of HIV positive women and women with HIV positive husband

Summary of the original title:

The introduction of Acceptance and commitment Therapy to improving the sexual health of women with HIV

Bokaie Mahshid ${ }^{1}$, Tahery Naiersadat*2, Dafeei Mariam³ ${ }^{3}$

1. PhD in Reproductive Health, University of Medical Sciences, Shahid Sadoughi School of Nursing and Midwifery, Yazd, Iran. mah bokaie@yahoo.com

2. MS in Midwifery Counseling, University of Medical Sciences, Shahid Sadoughi School of Nursing and Midwifery, Yazd, Iran, Responsible author. taherynaier@yahoo.com

3. PhD in Reproductive Health, University of Medical Sciences, Shahid Sadoughi School of Nursing and Midwifery, Yazd, Iran. maryam dafei@yahoo.com

\begin{abstract}
Background: AIDS is a progressive, incurable and preventable viral disease that damages the immune system and causes opportunistic infections. The discovery of methods of transmission, prevention and treatment of the disease has prevented researchers from considering the psychological consequences of the disease. On the other hand, discrimination associated with the
\end{abstract}


disease, adherence to complex treatment regimens and tolerating their side effects, analyzing physical strength and finally fear of disclosing the disease to the sexual partner exacerbate patients' psychological dissatisfaction and consequently changes their sexual behavior pattern. The present study attempts to investigate the extent of sexual satisfaction of HIV-positive women and their HIV-positive spouses using the Acceptance and Commitment Therapy (ACT).

Methods: This double-blind study was performed in 2019 with the aim of investigating the effect of treatment of HIV-positive women and their HIV-positive spouses referred to Behavioral Disease Counseling Center in Yazd and Meybod. 32 eligible women were randomly divided into two groups of 16 and participated in 10 weekly 2-hour sessions. Larsson's demographic and sexual satisfaction questionnaire was used for data collection. Data analysis was done by descriptive statistics and parametric interventions in SPSS software version 16 and significance level 0.05.

Findings: There was no significant difference between the two groups in terms of demographic variables. Mean scores of sexual satisfaction before (90.87 \pm 13.3$)$ and after intervention (96.31 \pm 12.94$)$ and before and one month after the intervention (97.81 \pm 12.52$)$ were significantly different in the intervention group. Comparing the mean scores of sexual satisfaction immediately after the intervention and one month later in the intervention group was not significant $(\mathrm{P}=0.24)$. Also, sexual satisfaction was significant between the two groups after the intervention and one month later.

Conclusion: The results show that acceptance and commitment Therapy are effective in women with HIV exposure to improve sexual satisfaction. According to the results, it is suggested that this approach be used in order to increase the mental flexibility of patients to accept the disease and the suffering resulting from it, and finally to improve marital relationships and increase sexual satisfaction. In addition, the continuation of sexual health counseling for women is recommended.

Trial registration: IRCT20181213041956N1, registered November 2018

Keywords: HIV, ACT, Acceptance and Commitment Therapy, Sexual Satisfaction.

\section{Background}

One of the major problems in women with HIV is sexual dissatisfaction (1). Primarily, it is due to the emergence of the disease and the necessity of research into the methods of prevention, diagnosis, drug discovery and treatment of opportunistic infections to emphasize the importance of psychiatric care. Second, discrimination resulting from the disease hides the disease from sexual 
partner and causes dissatisfaction (3). Third, the cultural and social constraints and inappropriate health policies of the sexes make it untenable (4).

A meta-analysis examining the impact of HIV/STI-related behavioral interventions on AfricanAmerican women in the United States showed that all interventions reduced the risk of sexual behaviors and reduced the risk of transmitting the disease (5). Also, a study conducted on the quality of life of HIV-positive women and those who were sexually abused. The study showed that ACT was significant (6). A review of clinical trials in the field of sexual health shows that most interventions have been made to reduce and prevent the transmission of sexually transmitted diseases (STD) and AIDS. It seems that there has not been a study of behavioral changes around sexual issues that affect one's self-esteem (7) and this necessitates further investigation in this regard.

As the rise in overall trend of the disease and its health, social, economic, cultural and political implications, challenging human societies was one of the consequence of this disease. 38 million people live with the disease worldwide, and in 2016, UNAIDS estimated 66,000 people living with HIV in Iran. On the other hand, negative attitudes towards patients exacerbate fear, anxiety, hopelessness and depression and other mental problems in patients and severely affect their quality of life. Efforts to fight AIDS must include changing one's lifestyle, especially in sex, and this is not possible unless the individual has sexual satisfaction. A study done in Canada on human living with HIV showed that the community under study had no sexual activity or had low sexual satisfaction, and this problem is rooted in stigma caused by the disease (4). Therefore, treating these patients with some of the psychological traits is essential for survival $(4,8)$.

Humans find many of their inner feelings, emotions, or thoughts disturbing. They are constantly trying to change or get rid of their inner experiences. These attempts to control are ineffective, and in a contradictory way, intensify the emotions and thoughts. In dealing with the acceptance and commitment therapy, the individual communicates with his or her inner experiences (bodily feelings, emotions, and thoughts). Then, he or she takes steps to change the shape or frequency of these events (acceptance) and finally to deal with difficult conditions. The goal of treatment processes is to increase psychological flexibility, ability to behave in accordance with important personal values, acceptance, and being present in the experience of pain. This method includes exposure-based exercises, language metaphors, and techniques such as mental care (9).

Researchers have proposed ACT as a treatment for depression (10), post-traumatic stress disorder (11), and anxiety disorders (12), and have used it to improve quality of life. It seems appropriate to use this approach in HIV patients who require psychological and social care to improve their quality of life (13). On the other hand, this approach is new and studies show that therapeutic advances in acceptance and commitment therapy are more effective than other traditional therapies and have more lasting effects on patients' quality of life (14). These benefits prompted the researcher to examine the impact of group counseling with a compassionate acceptance and commitment therapy on sexual satisfaction in women at risk of HIV. 


\section{Methods}

This study was performed using the intervention group and the Waitlist control group. Obtaining permission from the research vice-president and receiving the code of ethics of the statistical population, this study was a census-based sampling method among all HIV positive and at-risk women (with HIV-infected spouse) who went to the counseling center of Behavioral Diseases in Yazd and Meybod.

Inclusion criteria for the study included: Iranian citizenship, having HIV, the participant or his / her spouse, having spent at least one year of life together, not having a severe or debilitating mental illness, in himself/ herself or the spouse, having no disorder in Sexual function in himself/ herself and spouse, permanent monogamous cohabitation, desire to collaborate in research. Exclusion criteria were: unforeseen occurrence (illness or death of first-degree relatives). Criteria for omission were: absenteeism for more than three sessions, failure to perform therapeutic tasks over $30 \%$ during the research period.

The sampling took one week. Therefore, 32 participants (12 from Meybod center and 20 from Yazd center) were included in the study. Twelve women in the intervention group were HIV positive and four healthy and spouses of HIV positive. In the Waitlist control group, 10 HIVpositive women, six healthy women, and the spouse of the HIV-positive person were included. Individuals with full knowledge of all procedures and conditions for participation in this study, and the right to freely participate or not to participate in the study, completed the informed consent form. After obtaining written consent, participants were randomly divided into two groups of 16 intervention and Waitlist control groups.

\section{Data collection tools}

The tools were demographic information questionnaire and Larson sexual satisfaction questionnaire. A demographic questionnaire including demographic data such as age and education, research units' occupation, age and education of spouse, duration of the marriage, history of a previous marriage, number of children, presence of HIV in the research unit, presence of HIV disease in the spouse, overall spouse satisfaction and enough family income. The Larson Sexual Satisfaction Questionnaire was developed by Larson et al. In 1998 and consists of 25 questions using a 5-scale Likert questionnaire that measures overall sexual satisfaction. The calculated alpha for this questionnaire was 0.93 . Answers to the questions on the 5-scale are based on a Likert scale of 1 to 5, with the following options: Never receiving a score of 1, rarely a score of 2, sometimes a score of 3 , most often a score of 4 , and always a score of 5 . The following questions are scored as follows: 1-2-3-10-12-13-16-17-19-21-22 and 23, and the other questions are scored in reverse. The option never receives a score of 5, rarely a score of 4 , sometimes a score of 3, most often a score of 2, and always a score of 1 . Based on this questionnaire, the scores generally range from 25 to 125 and classify sexual satisfaction into levels of sexual dissatisfaction (score below 50), low satisfaction (score between 51 to 75), moderate satisfaction (score between 76 and 100) and High satisfaction (score above 101). It is worth mentioning that in the study of Shams Mofrahi (2001) entitled "Investigating the Effect of Marital Counseling on Couples' Sexual 
Satisfaction," the validity and reliability of this questionnaire were reported 0.90 and0.86 respectively. Also, during the Bahrami research on the relationship between sexual satisfaction and depression between fertile and infertile couples, the reliability of this questionnaire by Cronbach's alpha coefficient for the fertility group was 0.93 and for the infertile group was 0.89 (15).

Questionnaires were completed by the participants in the presence of the researcher, and their questions were answered in ambiguous situations. In one case of an illiterate participant and one participant with severe hand tremor, the independent researcher read the questions to the participant and considered their answers, and at the end of each fingerprint was recorded. Then, the intervention group participated in Acceptance and Commitment Therapy sessions in 10 sessions of 90 minutes in the morning and in group mode, once a week, in each center individually according to the ACT treatment plan. At the end of each session, participants were given assignments, which according to the content of each session, feedback of emotions, thoughts, etc. in the form of games, completion of the tables, etc. were requested by the participant at the beginning of the next session in the presence of others. It was reviewed, and the amount of learning was measured by the researcher, and bugs were fixed, and previous lessons learned. The waitlist control group did not receive treatment and were on routine counseling (family counseling, child, methadone therapy, communication skills, etc.) and were on the waiting list. The study was conducted by a researcher who participated in the ACT Advanced Foundation Courses and obtained a Certificate of Completion. After the intervention, both groups received postintervention. One month after the intervention, both groups were followed up again. After the end of the research process, two brief consultations were held for the waiting group.

\section{Result}

Data were analyzed by SPSS software version 16 after collection and coding. At first; frequency, percentage, mean and standard deviation were determined using descriptive statistics. Then, the significance level of intervention was measured with Chi square test and T test, which was more than 0.05 in all cases. Continuously, Independent $t$ test was used to compare the pre and post means in each intervention group and Paired $t$ test expectation intervention. In all interventions, $p<0.05$ was considered statistically significant.

The mean and standard deviation of age was $36.88+/-8.1$ in the intervention group and $34.5+/-$ 10.31 in the expectation group. The mean and standard deviation of spouse age was $40.13 \pm 7.46$ in the intervention group and 38.63 9. 9.39 in the expectation group. All participants had lower income than inadequate. The results indicated that the two groups had similar underlying variables such as education level, education level of spouses, duration of marriage, number of children, spouse satisfaction, sexual satisfaction, HIV status in the study unit, spouses' HIV prevalence of the study participants, and all participants' earning was less than adequate (Table 1). 
According to Table 2, the distribution of data on sexual satisfaction scores at different stages of the study using the Kolmogorov-Smirenov intervention had a normal distribution $(\mathrm{P}<0.05)$, so parametric interventions were used in this study.

Independent t-test results showed that pre-intervention sexual satisfaction scores were not significantly different between the two groups $(\mathrm{P}=0.277)$, but the mean changes were significantly different between the two groups after the intervention $(p=0.044)$. Paired t-test intervention results also showed that the mean score of sexual satisfaction was significantly reduced $(p=0.019)$ before and after the intervention in the intervention group, but there was no significant difference before and after the intervention in the expectation group $(\mathrm{p}=0.273)$ (Table 3).

As it can be seen in Table 4, the results of the independent t-test indicated that pre-intervention sexual satisfaction scores were not significantly different between the groups $(p=0.277)$, but the mean changes were significantly different between the two groups $(p=0.021)$ one month after intervention. Paired t-test results also showed that the mean score of sexual satisfaction was significantly decreased $(\mathrm{p}=0.006)$ before and one month after the intervention in the intervention group, whereas the mean score of sexual satisfaction did not decrease significantly $(p=0.682)$ in the expectation group before the intervention and one month after intervention.

Post-intervention sexual satisfaction score was significantly different between the study groups ( $\mathrm{P}$ $=0.044)$ and this difference was still significant one month after intervention $(P=0.021)$. Paired t-test intervention results also showed that the mean score of sexual satisfaction was not significantly different between one month after the intervention and the immediate results after the intervention $(\mathrm{P}=0.24)$ in the intervention group. In the expectation group, the mean score of sexual satisfaction was not significantly different between one month after the intervention and the immediate results after the intervention $(\mathrm{P}=0.682)$. (Table 5)

\section{Discussion}

The purpose of this study was to investigate the effect of group counseling with the acceptance and commitment therapy on sexual satisfaction of women with HIV and women with HIV-infected spouse.

The results of the study showed that the mean score of sexual satisfaction increased significantly in the study group compared to the control group immediately after the intervention which was corresponded to the studies of Josephson (6), Patterson (16), Moitra (17, 18), Saremi Nej

ad (19), Mohammadi (20), Samadi (21), Morshedi (22), Atiq (23), Mousavi (24). Josephson achieved similar results in a pilot study by executing two ACT sessions on HIV patients (6). In a case study, Patterson described the effectiveness of ECT approach in the treatment of distressed couples (16). In two separate studies in 2015 and 2017, Moitra examined the impact of behavioral therapy with the acceptance approach on HIV acceptance and disclosure, and adherence to AIDS care and treatment, and found positive results $(17,18,25)$. The results of the Patterson, Josephson and Moitra (2015) show that although the ACT approach is designed for eight sessions, it is also 
effective with fewer sessions. Saremi Nejad examined sexual satisfaction (19), Samadi- marital compatibility (21), Morshedi- marital depreciation (22), Atiq- sexual satisfaction (23), and Mousavi- marital satisfaction (24) based on ACT approach and their research results are corresponded to this research. Amirkhani showed that mindfulness was effective on marital conflict in HIV patients (26). The treatment is based on acceptance and approach commitment is based on the values. However, ACT principles and methods is originally developed as a form of psychotherapy, but at the present it is applied in many cases, from stress management to eating disorders. In acceptance and commitment based treatment, it is believed that thoughts are a natural mind's products. The association of the individual with the thoughts' content converts the thoughts to the beliefs. The Acceptance and Commitment based treatment helps clients remain resilient to their mental thoughts and rules, and instead of that, find different ways to interact more effectively with the world they are experiencing directly through intervention related to cognitive fault (10, 27). the ACT encourages couples to join to the real values of their lives and be enchanted by them, which can be found in relationships with their spouses throughout their lives (28). Although research differences are: the number of sessions, the type of questionnaire, and the community of study, it seems that acceptance and commitment treatment has helped couples with their abilities and traits to develop emotions, feelings, experiences, thoughts and experience physical symptoms in a new way to reduce conflict with negative reactions and increase thought acceptance. So, women of the intervention group have been able to decrease their sensitivities and expectations significantly by practicing concentration and acceptance, and as a result sexual satisfaction increased significantly. The women learn to accept their husbands as they are without judgment, humiliation, insult and comparison through the practice of acceptance and fault. However, Turkestan showed in a study that there is no difference between the conventional method of premarriage counseling and the ACT counseling on couples' sexual satisfaction. Choosing a very short time before a marriage or immediately after a marriage has not been effective to train with methods such as the acceptance and commitment therapy, because the couples have a particular excitement at this time and do not face problems that need to receive counseling. Turkestan suggested conducting more sample surveys by selecting a target group who got married between one and five years (29).

The results of the study showed that the mean score of sexual satisfaction increased one month after the intervention in the intervention group as compared to the expectation group and was statistically significant $(\mathrm{P}=0.021)$, so the second hypothesis of the research as: "the sex score was different one month after the intervention in the two groups (intervention and expectation)" was confirmed. Based on this finding, it can be concluded that the effect of counseling with the ACT approach was also sustained for women up to one month after the sessions. There is not any similar research which examine the post-intervention pursuit process with the ACT approach on the sexual satisfaction. Some studies did not pursuit $(6,19-23,26)$. Patterson showed the effect of ACT on distress expectation between couples at the 6-months pursuit after intervention (16). Mohammadi showed that ACT had a lasting effect on depression in women with marital conflict at the three- 
month pursuit (20). Christine showed the lasting effect of ACT on marital satisfaction and couples' mental health at the 3-months pursuit (30).

The studies show that faulting practices help authorities to interact with physical self-concept in a different way, resulting in increased psychological flexibility. When authorities do not behave in accordance with their thoughts and behave in accordance with their individual values (not thoughts), they will have a new experience. this change in performance and doing committed work also can lead to a change in people's attitudes towards their sexual satisfaction and marital adjustment, as well as a happy life and a better quality of life for the couple. In general, it helps the individual to communicate completely with the present and the conscious mind to change their behaviors and misconceptions, so that the couple can be fully satisfied with their lives, solve their problems and get a mutual agreement $(6,31)$.

Another part of the research findings showed that "sexual satisfaction score was different in the intervention group, before the intervention and immediately after the intervention." The results of the studies of Josephson, Patterson, Saremi Nejad, Mohammadi, Samadi, Morshedi, Atiq and Mousavi are consistent with this result. There was also a significant difference in the mean score of sexual satisfaction before and one month after the intervention $(\mathrm{P}=0.006)$, indicating a lasting effect of counseling with ECT approach on participants one month after the intervention compared to before the intervention.

Concerning the fifth hypothesis of the study, the difference between the mean score of sexual satisfaction immediately after the intervention and one month after the intervention in the intervention group was not significant $(\mathrm{P}=024)$ and therefore the hypothesis is rejected. Patterson showed a lasting effect of ACT at distress expectation between couples at 6-months pursuit after intervention (16). Mohammadi showed that ACT has a lasting effect on depression of the women with marital conflict at the three-month pursuit (20). Other similar studies did not have any pursuit periods $(21,22,24)$. It should be noted that although the mean score of sexual satisfaction increased from 90.87 to 96.31 before and after the study and the results were statistically significant, but the participants still had a moderate range of satisfaction in interpreting the Larson sexual satisfaction questionnaire. Research limitations, the lack of 13 people entering the study due to lack of entry criteria, and the lack of three people unwilling to participate in the study, may have contributed to this. Although the mean score was significantly different before and after the intervention in the intervention group in Atiq's study, there was no difference in sexual satisfaction as defined in Larson questionnaire (23).

\section{Conclusion}

The results of the study showed that sexual satisfaction in the counseling group with OCT approach improved significantly compared to the expectation group, which is consistent with the first, second and third hypotheses. In this study, comparing the mean score of sexual satisfaction was not significant immediately after the intervention with one month after the intervention, indicating that the counseling lasts up to one month after the intervention. 
According to the results of this study, it is suggested that treatment with acceptance and commitment therapy can be used in order to increase the mental flexibility of patients to accept the disease and the suffering resulting from it, and to continue committed behavior throughout life and to improve marital relationships and increase sexual satisfaction.

\section{Declarations}

\section{Abbreviations}

AIDS: Acquired Immuno Deficiency Syndrome

HIV: Human Immunodeficiency Virus

ACT: Acceptance and Commitment Therapy

UNAIDS: United Nations Programme on HIV/AIDS

\section{Ethics approval and consent to participate}

The present study was registered in the Ethics Committee of Yazd Shahid Sadoughi Medical Sciences University with Ethics Code (IR.SSU.REC.1397.110) and IRCT Code (IRCT20181213041956N1). Providing information about the research process and timing, the type of intervention, the necessity for written informed consent, the assurance of confidentiality of the sessions, the freedom to leave the study at any stage of the research were the ethical considerations.

\section{Consent for publication}

Participants agreed to publish the results of the research without mentioning the name by completing the conscious consent form. This form was reviewed and finalized in the ethics committee of Shahid Sadoughi University of Medical Sciences in Yazd.

\section{Availability of data and material}

Data and materials are available on request.

\section{Competing interests}

No Competing interests

\section{Funding}

The present study is part of the master's thesis of midwifery counseling, which was conducted with the financial support of the Vice Chancellor for Research of Shahid Sadoughi University of Medical Sciences in Yazd.

\section{Authors' contributions}


MB has developed a clinical trial protocol and led the study, supervised the study and participated in the writing of the manuscript. NT conducted sampling and counseling sessions. Gathered the data and performed the statistical process and played an important role in writing the manuscript. MD performed statistical analysis and interpreted the data and was involved in writing the manuscript. All authors read and approved the final version.

\section{Research limitations}

Using the sampling method based on inclusion and exclusion criteria due to restriction of women with or with HIV-positive mate referred to behavioral counseling centers and absence of males that do not acquire the reciprocal effect of training men, existence of training outside the scope of research, for example, through broadcasting organization and the survey of infected women and healthy women with an infected spouse in a statistical population are the limitations of this research. Using the mean score in the statistical analysis is also resulted in low sexual satisfaction of the individuals with low sexual satisfaction even at the end of the study, which lead to the lower mean score of the study group.

\section{Acknowledgments}

The present study is a part of a Master's thesis in Midwifery Counseling conducted with the financial support of the University's Vice-Chancellor for Research. We would like to thank the Vice-Chancellor for Research and Technology, Health Deputy of Yazd Shahid Sadoughi University of Medical Sciences, the reverent professors and the staff of Yazd and Meybod Behavioral Disease Counseling Centers, as well as the women with HIV / AIDS who gave their time for this research. 


\section{References:}

1. Schönnesson LN, Zeluf G, Garcia-Huidobro D, Ross MW, Eriksson LE, Ekström AM. Sexual (Dis) satisfaction and its contributors among people living with HIV infection in Sweden. Archives of sexual behavior. 2018; 47(7):2007-26. doi: 10.1007/s10508-017-1106-2.

2. Haghdoost AA, Mostafavi E ,Mirzazadeh A, Navadeh S, Feizzadeh A, Fahimfar N, et al. Modelling of HIV/AIDS in Iran up to 2014. Journal of AIDS and HIV Research. 2011;3(12):231-9. doi: 10.5897/JAHR11.030. (Persian)

3. Jafari S, Farajkhoda T, Baghiani Moghadam MH, Minoo Mohraz M. Iranian infected women experiencing health providers'stigma agains HIV/AIDS: Dos and Dont in the Case of HIV/AIDS Treatments.Ambient Science, 2017: Vol. 04(Sp1).

doi:10.21276/ambi.2017.04.sp1.ga02. (Persian)

4. Kaida A, Carter A, de Pokomandy A, Patterson S, Proulx- Boucher K, Nohpal A, et al. Sexual inactivity and sexual satisfaction among women living with HIV in Canada in the context of growing social, legal and public health surveillance. Journal of the International AIDS Society. 2015; 18: 20284. doi: 10.7448/IAS.18.6.20284.

5. Crepaz N, Marshall KJ, Aupont LW, Jacobs ED, Mizuno Y, Kay LS, et al. The efficacy of HIV/STI behavioral interventions for African American females in the United States: a meta-analysis. American journal of public health. 2009; 99(11): 2069-78. doi: 10.2105/AJPH.2008.139519.

6. Josefson L. Acceptance and Commitment Therapy for women affected by HIV, Pain and Sexual abuse. A pilot study in Sierra Leone. 2012. http://www.diva-

portal.org/smash/record.jsf?pid=diva2:585254

7. Cooper B, Toskin I, Kulier R, Allen T, Hawkes S. Brief sexuality communication - a behavioural intervention to advance sexually transmitted infection/HIV prevention: a systematic review. BJOG: An International Journal of Obstetrics \& Gynaecology. 2012: 1:14. (s5): 92-103.

https://doi.org/10.1111/1471-0528.12877.

8. productive health and HIV interventions: a systematic review. Journal of the International AIDS Society. 2010; 13(1): 26. doi: 10.1186/1758-2652-13-S1-S5

9. Hayes SC, Kennedy CE, Spaulding AB, Brickley DB, Almers L, Mirjahangir J, Packel L, et al. Linking sexual and re Strosahl KD, Wilson KG. Acceptance and commitment therapy: American Psychological Association; 2009.

10. Rajabi G, Gashtil K, Amanallahi A. The relationship between self-compassion and depression with mediating's thought rumination and worry in female nurses. Iran Journal of Nursing.

2016;29(99):10-21. DOI: 10.29252/ijn.29.99.100.10. (Persian)

11. Orsillo SM BS. Acceptance and Commitment Therapy in the treatment of posttraumatic stress disorder. Behav Modif 2005;29(1): 95-129.

12. Clark MF. Information processing in social phobia. Biol Psychiatry. 2002;51(1):92. DOI:10.1016/s0006-3223(01)01296-3

13. Hayes SC LJ, Bond FW, Masuda A, Lillis J, Acceptance and commitment therapy: model, processes and outcomes. Journal of Behavior Research \& Therapy 2006;44(1):1-25.

DOI:10.1016/j.brat.2005.06.006

14. Forman EM, Shaw JA, Goetter EM, Herbert JD, Park JA, Yuen EK. Long-term follow-up of a randomized controlled trial comparing acceptance and commitment therapy and standard cognitive 
behavior therapy for anxiety and depression. Behavior therapy. 2012;43(4):801-11. doi: 10.1016/j.beth.2012.04.004.

15. Larson JH, Anderson SM, Holman TB, Niemann BK. A longitudinal study of the effects of premarital communication, relationship stability, and self-esteem on sexual satisfaction in the first year of marriage. Journal of sex \& marital therapy. 1998; 24(3): 193-206.7. doi: 10.1080/00926239808404933

16. Patterson S, Cescon A, Samji H, Chan K, Zhang W, Raboud J, et al. Life expectancy of HIV-positive individuals on combination antiretroviral therapy in Canada. BMC infectious diseases. 2015; 15(1): 274 . doi: 10.1186/s12879-015-0969-x

17.Moitra E, Chan PA, Stein MD. Open trial of an acceptance-based behavior therapy intervention to engage newly diagnosed HIV patients in care: rationale and evidence of feasibility and acceptability. Behavior modification. 2015; 39(5): 670-90._doi: 10.1177/0145445515590977

18. Moitra E, Herbert JD, Forman EM. Acceptance-based behavior therapy to promote HIV medication adherence. AIDS care. 2011; 23(12): 1660-7. doi: 10.1080/09540121.2011.579945

19. SaremiNezhad Mehdi SL. The effect of acceptance and commitment therapy on sexual satisfaction of couples in Shiraz. International Journal of Medical Research \& Health Sciences. 2017; 6(1): 58-65.

(Persian)

20. MOHAMMADI E ,KESHAVARZI AF, FARZAD VA, SALEHI M. THE EFFECTIVENESS OF ACCEPTANCE AND COMMITMENT THERAPY (ACT) ON MARITAL SATISFACTION AMONG DEPRESSED WOMEN. 2016 (Persian).

21. Samadi H, Mohsen D. Investigating the effectiveness of Acceptance and Commitment Therapy (ACT) on marital compatibility and life expectancy in infertile women. International Academic Journal of Sosial Sciences. 2016;3(5):16-27. (Persian)

22. Morshedi M, Davarniya R, Zahrakar K, Mahmudi M, Shakarami M. The Effectiveness of Acceptance and Commitment Therapy (ACT) on Reducing Couple Burnout of Couples. Iranian Journal of Nursing Research. 2016; 10(4): 76-87. (Persian)

23. Chalal Ghochan Atiq Y, Sarai, Fatima. The Effectiveness of Acceptance and Commitment Therapy on Marital Adjustment, Sexual Satisfaction and Satisfaction with Women's Life. Journal of Basic Principles of Mental Health. 1395; 18 (Special Issue of the 3rd International Conference on Psychology and Educational Sciences): 527-33. (Persian)

24. MOOSAVI MS, RASHIDI A, GOLMAHAMMADIAN M. Effectiveness of acceptance and commitment therapy on increasing marital satisfaction of the veteran and freedman wives. 2015. (Persian) 25. Moitra E, LaPlante A, Armstrong ML, Chan PA, Stein MD. Pilot randomized controlled trial of acceptance-based behavior therapy to promote HIV acceptance, HIV disclosure, and retention in medical care. AIDS and Behavior. 2017; 21(9): 2641-9. doi: 10.1007/s10461-017-1780-z.

26. Amirkhani M. MINDFULLNESS BASE COGNETIVE THERAPY ON MARRITAL CONFILICT IN HIV+/AIDS PATIEN. The Journal of Urmia University of Medical Sciences. 2016;27(3):198-207. (Persian)

27. Hero L-M, Lindfors E, Taatila V. Individual Innovation Competence: A Systematic Review and Future Research Agenda. International Journal of Higher Education. 2017;6(5):103-21. doi: https://doi.org/10.5430/ijhe.v6n5p103

28. Hofmann SG AG. Acceptance and mindfulness-based therapy: new wave

or old hat? . Clin Psychol Rev. 2008;28(1):1-16. doi: 10.1016/j.cpr.2007.09.003. 
29. Akbari Torkestani N, Ramezan nejad P, Abedi M, Eshrati B, Movahed Majd, Majeed, Nekoobahr A. EFFECT OF PREMARITAL COUNSELING WITH ACCEPTANCE AND COMMITMENT THERAPY-BASED APPROACH ON SEXUAL SATISFACTION. Journal of Nursing and Midwifery Urmia University of Medical Sciences. 2017; 15(4): 244-51. URL: http://unmf.umsu.ac.ir/article-1-3175en.html(Persian)

30. Christensen A, Atkins DC, Berns S, Wheeler J, Baucom DH, Simpson LE. Traditional versus integrative behavioral couple therapy for significantly and chronically distressed married couples. Journal of consulting and clinical psychology. 2004; 72(2): 176. doi: $\underline{10.1037 / 0022-006 X .72 .2 .176}$

31. Hayes-Skelton SA, Roemer L, Orsillo SM. A randomized clinical trial comparing an acceptancebased behavior therapy to applied relaxation for generalized anxiety disorder. Journal of consulting and clinical psychology. 2013; 81. (5): 761-73. doi: 10.1037/a0032871 


\section{Supplementary Files}

This is a list of supplementary files associated with this preprint. Click to download.

- table.1.pdf

- Flowchartofparticipantsinvariousstagesofresearch.pdf 